\title{
Sağlık Kuruluşlarında Halkla İlişkilerin Etkinliğini Ölçme: Özel ve Kamu Sağlık Kuruluşlarının Karşılaştırılması ${ }^{1}$
}

\author{
Engin ÇELEBi ${ }^{2}$
}

Başvuru Tarihi: 16.12.2019～Kabul Tarihi: 25.02.2021

Makale Türü: Araştırma Makalesi

\section{Öz}

Kuruluşlar için halkla ilişkiler biriminin değeri hedef kitlelerle sürdürülen ilişkilerin kalitesine dayanmaktadır. Sağlık kuruluşlarına karşı duyulan memnuniyet, güven ve bağlllı duygusunun ise psikolojik ve sosyal gerçeklikleri vardır. Bu yüzden sağlık hizmeti alıcılarının sağllk kuruluşları tercihlerini anlamak ve olumlu ilişkisel sonuçlara ulaşabilmek için yeni ve farkl stratejiler gerekebilir. Bu stratejiler içinde ise halkla ilişkilerin ve etkili iletişim tekniklerinin rolünü araştırmak gerekmektedir. Bu çalışmanın amacı sağlık kuruluşlarında halkla ilişkiler çalışmalarının etkisini ölçmek ve hedef kitlelerin duygusal ve davranışsal tutumları üzerindeki etkisini belirlemektir. Araştırma özel ve kamu sağlık kuruluşlarından düzenli olarak en az 3 ay hizmet alan 249 sağlık hizmeti alıcısı üzerinde uygulanmıştır ve sonuçların karşılaştırılması amaçlanmıştır. Araştırma sonucuna göre halkla ilişkilerde ilişkisel sonuçların hem özel sağlık kuruluşlarında hem de kamu sağlık kuruluşlarında sağlık hizmeti alıcılarının duygusal ve davranışsal tutumları üzerine olumlu etkisinin olduğu ortaya çıkartılmıştır. Hem kamu hem de özel sağlık kuruluşlarında en önemli boyutlar güven ve memnuniyet olarak ölçülmüş̧ür. Her iki sağllk kuruluşu sektöründe de ilişkisel sonuçlar arasında anlamlı bir korelasyon vardır ve olumlu sonuçlar benzerlik göstermektedir. Sonuç olarak, sağglk kuruluşlarının halkla ilişkiler algılamalarını güçlendirmenin aynı zamanda sağlık kuruluşlarına olan olumlu toplumsal algıyı ve kurumsal itibar algısını güçlendirmek anlamına gelebileceği bulgusuna ulaşılmıştır.

Anahtar Kelimeler: Halkla İlişkiler, İlişki Yönetimi, Sağlık Kuruluşları, İletişim Yönetimi, Kurumsal İletişim

Atıf: Çelebi, E. (2021). Sağlık kuruluşlarında halkla ilişkilerin etkinliğini ölçme: Özel ve kamu sağlık kuruluşlarının karşılaştırılması. Anadolu Üniversitesi Sosyal Bilimler Dergisi, 21(1), 81-98.

\footnotetext{
${ }^{1}$ Bu çalışma 2019 ylı içerisinde dergiye yayın başvurusunda bulunulmuş makale olduğundan geriye dönük etik kurul izni gerekmemektedir.

${ }^{2}$ Çukurova Üniversitesi A.S. Sağlık Hizmetleri Meslek Yüksekokulu Tıbbi Hizmetler ve Teknikleri Bölümü, engincelebi@cu.edu.tr, ORCID: 00000001-5791-8080
} 


\section{Giriş}

Halkla ilişkiler çalışmalarının amacı duygusal, düşüncesel ve davranışsal desteğe yönelik bir bilinç oluşturmak ve tutumsal bir etki yaratmaktır. $\mathrm{Bu}$ amacı gerçekleştirme becerisi aynı zamanda hedef kitlelerin motivasyonuyla ilgili bir süreçtir. Bu yüzden halkla ilişkiler çalışmalarının ortak değerlere ve deneyimlere ait anlamlar taşıması gerekmektedir. Ayrıca, halkla ilişkiler uygulamalarının etkililiğine yönelik arzulanan sonuçlara ulaşabilmek için hedef kitlelerin ihtiyaçlarının, beklentilerinin ve endişelerinin anlaşılması gerekmektedir. $\mathrm{Bu}$ yüzden hedef kitle odaklı bir perspektifle ilişkisel sonuçlara odaklanmak halkla ilişkiler uygulamalarının odak noktası haline gelmiştir.

İletişimsel süreçte hedef kitlelerin görüşlerinin dikkate alınması onlarla etkileşim kurmak kadar değerlidir. Böylece daha iyi ve uzun süreli ilişkiler kurulabileceği öngörülebilir. Bu yüzden halkla ilişkiler uygulayıcıları temsil ettikleri kuruluşlarda; hedef kitle gruplarının hangi ilişkisel boyutlara diğerlerine göre öncelik verdiğini, bu boyutlar arasında neden-sonuç ilişkisinin olup olmadığının ve bunların nedensel bağlantıları belirlemek durumundadır (Çelebi, 2019).

Coombs ve Holladay'e (2007) göre halkla ilişkiler birimleri genellikle kuruluşlar içinde stratejik kararlar verme gücüne sahip değildir. Ancak halkla ilişkiler birimleri çeşitli paydaş bakış açıları ve çatışmalarını/fikir ayrılıklarını tanımlayarak yönetime en iyi şekilde hizmet edebilmelidir. Halkla ilişkiler teori ve uygulamalarında ilişki yönetimi büyük önem taşımaktadır. İlişki yönetimi simetrik iletişimi ve işbirliğine dayalı karar alma sürecini gerektirmektedir. İlişki yönetiminin merkezinde sorumlu davranmak ve birey merkezli olmak vardır. Birey merkezli olmak duygu, düşünce, istek ve endişelere odaklanmayı gerektirmektedir. Bu çalışmanın amacı ise sağlık kuruluşlarında ilişkisel boyutların önem derecisini açıklamak, ilişkisel sonuçları iletişimsel becerilerle tahmin edebilmek ve böylece sağlık kuruluşlarında halkla ilişkilerin değerini ortaya çıkarmaktır.

Sağlık kuruluşlarında halkla ilişkilerin değerinin ortaya çıkartılması için öncelikle kurumsal halkla ilişkilerin tanımlanması, kurumsal halkla ilişkilerin öneminin kurumsal sonuçlarla ilişkilendirilmesi ve ilişkisel kalitenin ölçülmesi gerekmektedir. Sağlık kuruluşları farklı özelliklere sahip hedef kitle gruplarıyla ilişkilerini sürdürmektedir. Her bir hedef kitle grubuna yönelik ilişkisel sonuçların önemini ve etki derecesini anlamak etkili uygulamalar geliştirilmesi için gereklidir. Sağlık kuruluşlarında hedef kitle üyelerinin talep ve beklentilerinin farklılık gösterebilmesinden dolayı halkla ilişkilerin sağlık kuruluşlarında nasıl organize edildiği, nasıl algılandığı, işlevi, sorumlulukları, görevleri ve etkilerinin anlaşılması gerekmektedir.

Literatürde halkla ilişkilerin iletişim yönetimi, sorun yönetimi, kriz yönetimi, ilişki yönetimi ve gündem yönetimi vb. fonksiyonları ile ilişkili tanımları mevcuttur. Dahası halkla ilişkiler itibar yönetimi, imaj yönetimi, müşteri ilişkileri yönetimi, sosyal sorumluluk uygulamaları, sosyal medya yönetimi vb. çok farklı alan ile ilişkilendirilmektedir. Amaç her ne olursa olsun halkla ilişkiler uygulamaları ile arzulanan ilişkisel sonuçlara ulaşmak olumlu diyalog kurmayı, hoşgörü geliştirmeyi ve bağllık değeri yaratmayı gerektirir. Sağlık kuruluşlarının hedef kitleleri aynı zihniyete sahip kişilerden oluşmaz. Hedef kitleyi oluşturan bireyler içinde farklı insan türleri, fikirler ve duygular bulunabilir. Ortak stratejik yaklaşım ise güven vermeyi gerektirir ve 'güven' sağlık kuruluşlarında kritik öneme sahiptir. Bu çalışmanın amacı ise sağlık kuruluşlarında ilişkisel boyutların önem derecisini açıklamak, ilişkisel sonuçları iletişimsel becerilerle tahmin edebilmek ve böylece sağlık kuruluşlarında halkla ilişkilerin değerini ortaya çıkarmaktır. 


\section{Sağlık Kuruluşlarında Halkla İlişkilerin Önemi}

Sağlık kuruluşları kamu sağlığına yönelik toplum yararına hizmet eden kuruluşlardır. Halkla ilişkilerde ilişkisel sonuçlar sağlık kuruluşlarının sağlık hizmeti alıcıları ile kurmuş oldukları beşeri ilişkileri ölçebilen bir strateji olarak kullanılabilir. Sağlı kuruluşlarının sağlık hizmeti alıcılarıyla olan ilişkisel sonuçlarını güçlendirilmesi sağlık hizmeti alıcılarının sağlık kuruluşlarına olan duygusal ve davranışsal desteklerinin belirleyicisi olabilir.

Sağlık kuruluşları için toplumsal ilişkiler ve dış hedef kitle büyük önem arz etmektedir. Sağlık kuruluşlarının hedef kitleleri birçok farklı grubu içermektedir. Belirsizlikler yönetmek, kaygı ve endişeleri gidermek, sorunları çözmek gibi yaklaşımların sağlık kuruluşları ile hizmet alıcıları arasındaki ilişkilerin kalitesini etkileyebileceği söylenebilir. Bunun için sağlık hizmeti alıcıları kendi düşünce ve fikirlerini rahatça ifade edebilmelidir. Çünkü eşitlik ve etkileşim olumlu ilişkisel sonuçlara ulaşmada önemli bir rol oynamaktadır.

Halkla ilişkiler algılamalarına yönelik en önemli katkı stratejik iletişimdir. Sağlık kuruluşlarında halkla ilişkilerin kurumsal amaç ve misyonlara yönelik stratejik bir iletişimsel çaba olduğu söylenebilir. Diğer yandan, Khodarahmi (2009) halkla ilişkiler ve stratejik halkla ilişkiler arasında iletişimsel açıdan farklılıklar olduğunu söylemektedir. Yazara göre "simetrik iletişim" ve "zamanlama" stratejik halkla ilişkiler hedeflerine ulaşmak için önemlidir.

Halkla ilişkiler teori ve uygulamalarının tarihsel süreç içinde tek yönlü iletişimden iki yönlü simetrik iletişime evrildiği söylenebilir. İki yönlü iletişimin amacı ilişkisel kaliteyi arttırmaktır. Çünkü ilişkisel kalite iki yönlüdür. Diğer kuruluşlarda olduğu gibi sağlık kuruluşlarında da halkla ilişkiler çalışanlarının amacı güven ve anlayışı arttırarak hedef kitle ilişkilerini güçlendirmektir. Bu yüzden ilişki yönetimi teorisinin sağlık kuruluşlarında değerli olabileceği söylenebilir.

Springston ve Lariscy (2005), sağlık kuruluşlarında halkla ilişkilerin etkinliğini araştırmış ve iki temel unsur bulmuştur: itibar yönetimi ve paydaş ilişkileri. Yazarlara göre (2005, s. 238) itibar yönetimi etik davranış, onurlu bir işyeri, etkin liderlik, kamuya odaklanma ve kaliteli sağlık hizmetlerinin güvenilir bir şekilde sunulması olarak tanımlanmaktadır. Springston ve Lariscy (2005, s. 238), kritik öneme sahip olan şu iki bileşenin yönetilmeden itibar yönetiminin sağlanamayacağını belirtmiştir: (1) halk sağlığı kuruluşlarını, özellikle de kriz zamanlarında, etkileyen sorunlar ve (2) paydaşlarla ilişkiler. Hem sorunların yönetimi hem de paydaş ilişkileri için ise en iyi uygulama alanının halkla ilişkiler olduğu söylenebilir.

Halkla ilişkiler tüm sağlık kuruluşları için gereklidir. Park ve Reber'e göre (2010, s. 52) halkla ilişkiler sağlık kuruluşlarının halk ile karşılıklı yarar sağlayan ilişkilerinin kolaylaştırılmasına olanak sağlar ve bunun sonucunda sağlık kuruluşları halk ile beraber daha sağlıklı bir toplum geliştirilmesi hedefine ulaşabilir.

Gordon ve Kelly (1999), “Hastanelerde Halkla İlişkiler Uzmanlığı ve Örgütsel Etkililik” üzerine yapmış olduğu araştırma sonucunda halkla ilişkilerde "iki yönlü simetrik modelin uygulanması”, "yönetici rolünün uygulanması" ve "stratejik planlamaya dahil olunması" ile "örgütsel etkinlik" arasında güçlü ve olumlu ilişkiler bulmuştur. Ayrıca Yazarlar, bir teknisyen rolü olarak geleneksel iletişimin (yüz yüze iletişim), hastanede halkla ilişkilerin mükemmelliği için bir temel oluşturduğunu tespit etmiştir.

Türkiye'deki sağlık iletişimi çalışmalarını inceleyen Becerikli (2013) sağlık alanındaki politikalara ve gündelik hayattaki izdüşümlerine mesafeli ve eleştirel bir tarzda bakılmadığı, genellikle ana akım iletişim çerçevelerine başvurulduğu ve yöntemsel olarak da insan tutum ve davranışını ölçmeye yönelik nicel araştırma tekniklerine odaklanıldığını söylemektedir. Duğan ve Uludağ’n (2015) sağlık kuruluşlarında yapmış olduğu araştırma sonuçlarına göre hastane personelinin büyük çoğunluğunun kurumlarında halkla ilişkiler biriminin varlığı ve işlevi hakkında yeterli bilgiye sahip olmadığı ve bu nedenle iç halkla ilişkilere daha fazla ihtiyaç olduğu sonucuna varılmıştır. 
Halkın tutumu olarak, görüş ve davranışlar genellikle bir halkla ilişkiler programının temel sonuçları olarak kabul edilmiştir (Ki ve Hon, 2007). Sağlık kuruluşlarında ilişkisel sonuçlara odaklanma ve bunların nasıl geliştirileceğinin yöntemlerini bulmak oldukça önemlidir. Sağlık kuruluşlarında ilişki kurma stratejileri oluşturulurken ilişkisel sonuçları (bağlılık, güven, memnuniyet) nelerin oluşturduğu ve bunları nelerin arttırdığı öngörülebilmelidir. İlişkisel sonuçlar sağlık kuruluşlarında duygusal, davranışsal ve tutumsal olarak ortaya çıkabilir. İlişkisel sonuçlar motivasyonel bir güçtür. Halkla ilişkiler uygulayıcıları ise istenilen olası sonuçlar hakkında tahminlerde bulunmalıdır. İlişki yönetimi sağlık kuruluşlarında etkili halkla ilişkiler süreç ve teknikleri ile mümkün kılınabilir. Bu sayede sağlık kuruluşlarında halkla ilişkiler hedef kitlelerle yüksek kaliteli ilişkilerin oluştuğu başarılı bir alana dönüşebilir.

\section{iliş̧kisel Sonuçlar ile Kurumsal Halkla iliş̧̧kilerin Etkinliğinin Ölçülmesi}

Kuruluşların hedef kitleleri ile olan ilişkilerinin derecesi ve kalitesi temel bir sonuçtur. Hedef kitleler ile olan ilişkilerin kalitesi birçok olumlu sonuç üretir. Beklentiler, deneyimler ve değerlerin uyumuyla olan ilişkisel kaliteye yönelik unsurlar ise psikolojik, karmaşık ve çok boyutlu kavramlardır (Heath, 2013, s. 426). Bu yüzden ilişkisel sonuçlar kuruluşların hedef kitleleri ile olan ilişki türleri esas alınarak incelenmelidir.

Etkileşim ilişkisel sonuçlara yönelik önemli bir faktördür. Ancak, hedef kitleler ile etkileşime geçmek onlarla ilişki kurmak anlamına gelmemelidir. İlişki yönetimi güven, bağlllık ve memnuniyetten etkilenen uzun vadeli ilişkiler kurmak ve sürdürmekle yürütülür. Hedef kitle ilişskilerini yönetmek için ilişkisel boyutların etki düzeyine odaklanılmalıdır. İlişki yönetimi halkla ilişkiler literatüründe önemli bir araştırma alanıdır. Amaç belirsizlikleri yönetmek, kaygı ve endişeleri gidermek, hedef kitlelerle uzun vadeli güçlü ilişkiler kurmak ve sürdürmektir.

Halkla ilişkilerde ilişki yönetimi, kuruluşlar ve hedef kitleleri arasında güçlü ve olumlu ilişkiler kurulmasına olanak tanıyan ve karşılıklı faydalar üreten bir yaklaşım olarak görülmektedir (Ledingham, 2008). Ferguson'un (2018) 1984 yılında dikkat çektiği ilişki yönetimi halkla ilişkilerin halen en çok kabul gören tanımlamalarından biridir. Amerika Halkla İlişkiler Derneği'nin (PRSA), halkla ilişkilerin tanımı ilişkisel etkiye odaklanarak halkla ilişkileri "kuruluşlar ve hedef kitleleri arasında karşllıklı olarak yararlı ilişkiler kuran stratejik bir iletişim süreci" şeklinde tanımlamaktadır.

Halkla ilişkilerde ilişkisel sonuçların etkinliğini ölçme kuruluşların pazarlama, sponsorluk, reklam ve kurumsal itibar gibi kurumsal başarılarını ölçmeden farklıdır. Kurumsal halkla ilişkilerin etkinliğini anlamak için iletişimsel sürece ve ilişkisel sonuçlara bakmak önemlidir. İlişki geliştirme stratejileri hem kuruluşun hem de hedef kitlenin yararına olanlara odaklanmaktır. Kurumsal halkla ilişkilerin etkinliğini ölçmek için çok farklı yaklaşımlar benimsenmiştir.

Halkla ilişkilerin duayenlerinden Hon ve Grunig (1999) kurumsal halkla ilişkilerin etkinliğini güven, memnuniyet, bağlılık ve karşlıklı kontrol unsurlarıyla ölçmektedir. Yazarlara göre: "Güven” bir tarafın kendisini diğer tarafa maruz bırakma konusundaki güven ve istekliliğini ifade eder ve bütünlük, güvenilirlik ve yetkinlik olmak üzere üç temel boyuttan oluşur. "Bağlılık” katılan tüm tarafların, ilişkinin harcanan zamana ve enerjiye değer olduğunu düşündüğünü belirtir. Bağlllık değerli ilişkileri sürdürmek için gereklidir. Çünkü Moorman vd.'ye (2012) göre bağlllık ilişkiyi sürdürme istekliliğidir. “İlişkisel Memnuniyet” tarafların ilişkiden ne ölçüde memnun kaldığı anlamına gelir. Memnuniyet faydaların derecesine dayanmaktadır. Memnuniyet ilişkisel sonuçların değerlendirmesinde uzun zamandan beri merkezi bir faktör olmuştur. "Karşılıklı Kontrol" ise tarafların diğerini etkileme hakkına kimin sahip olduğu konusunda mutabık kalındığı anlamına gelmektedir.

Sağlık hizmeti alıcılarının sağlık kuruluşlarına yönelik ilişkisel sonuçlarını ölçmek için Hon ve Grunig’in ölçeğinden yararlanılarak 20 maddeden oluşan anket oluşturulmuştur. Hon ve Grunig'in (1999, s. 19-20) 
kuruluş ve hedef kitle arasındaki ilişkisel değerlendirmelerin boyutlarını ölçen ve Halkla İlişkiler Enstitüsü için hazırlanan ölçeği halkla ilişkiler alanında geçerli ve güvenilir bir ölçektir ve halen birçok araştırmacı tarafından kullanılmaktadır (Sisson, 2015; Pressgrove ve McKeever, 2016; Jo, 2018; Kim, 2018; Dhanesh ve Duthler, 2019; $\mathrm{Ni}$, Xiao, Liu ve Wang, 2019).

Araştırma soruları oluşturulurken güven unsuruna yönelik "Bu sağlık kuruluşu çalışanları sağlık hizmeti alıcılarına karşı dürüst ve adil davranır”, karşılıklı kontrol unsuruna yönelik "Bu sağlık kuruluşu çalışanları sağlık hizmeti alıcılarıyla ilgilenirken kendisini üstün görmemektedir”, bağlılık ölçeğine yönelik "Sağlık hizmeti almak için genellikle bu sağlık kuruluşunu tercih ederim.”, memnuniyet ölçeğine yönelik "Bu sağlık kuruluşundan sağlık hizmeti almaktan memnunum” şeklinde ölçek maddeleri kullanılmıştır. İlişkisel sonuçlar tutumsal bir boyut ve bağımsız değişkenler olarak ele alınmıştır. Araştırma kapsamında aşağıdaki sorulara cevap aranmıştır.

Araştırma Sorusu 1: Sağlık hizmeti alıcıları sağlık kuruluşları tercihlerine yönelik isteklerini hangi ilişkisel boyut ile tanımlamaktadır.

Araştırma Sorusu 2: Sağlık hizmeti alıcılarının sağlık kuruluşları ile olan ilişkisel sonuçları (karşılıklı kontrol, güven, memnuniyet, bağlılık) arasında nasıl bir korelasyon vardır?

Araştırma Sorusu 3: Sağlık hizmeti alıcılarının sağlık kuruluşları ile olan ilişkisel boyutlarının derecesi kamu ve özel sağlık kuruluşlarında farklılık gösterecek midir?

Araştırma Sorusu 4: İlişkisel sonuçlar ile sağlık kuruluşlarının kurumsal itibarları arasında bir ilişki var midır?

\section{Sağlık Kuruluşlarında Kurumsal Halkla İlişkilerin Etkinliği Üzerine Bir Araştırma}

\section{Araştırmanın Metedolojisi}

$\mathrm{Bu}$ araştırmada halkla ilişkilerde ilişki yönetiminin etkinliği sağlık kuruluşları ile sağlık hizmeti alıcıları arasındaki ilişkilerin kalitesini ölçmek için kullanılacaktır. Böylece literatüre katkı sağlatılması amaçlanmaktadır. Araştırma kapsamına Türkiye'de sağlık kuruluşlarından hizmet alan sağlık hizmeti alıcıları dâhil edilmiştir. Özel sağlık kuruluşlarından hizmet alan 117 kişiye ve Kamu sağlık kuruluşlarından hizmet alan 132 kişiye anket uygulaması gerçekleştirilmiştir ve sonuçların karşılaştırılması amaçlanmıştır. Örneklemin \% 44'ünü ( $\mathrm{n}=110)$ kadınlar, \% 56'sını ise ( $\mathrm{n}=139)$ erkekler oluşturmuştur. Katılımcıların yaş aralığı ise şu şekildedir; 18-30 yaş arası 39 kişi, 31-40 yaş arası 57 kişi, 41-50 yaş arası 68 kişi ve 51 yaş ve üzeri 85 kişi. Veriler, katılımcılardan anket tekniği ile gönüllülük esasına göre toplanmıştır. Verilerin toplanması yaklaşık 4 ay (Eylül-Aralık 2019) sürmüştür. Araştırma için Girişimsel Olmayan Klinik Araştırmalar Etik Kurulundan etik kurul raporu alınmıştır (Yıl: 2019, Toplantı Sayısı: 86, Karar No: 13).

Örneklem seçiminde ölçüt örnekleme yöntemi kullanılmıştır. Bu ölçütlere yönelik olarak hizmet alınan sağlık kuruluşuna karşı bir tutum oluşumu için gereken süre 3 ay olarak belirlenmiştir ve anket uygulaması sağlık kuruluşlarından düzenli olarak en az 3 ay hizmet alan, 18 yaş üzerinde ve anket uygulamasına katılmaya gönüllü olan sağlık hizmeti alıcıları üzerinde uygulanmıştır.

Anket maddeleri 5'li likert ölçeğe göre (1-Kesinlikle katılmıyorum, 5- kesinlikle katıllyorum) ölçülmüştür. Anket Türkiye'de daha önceki araştırmalarda kullanılmıştır (Çelebi, 2020a). Ancak sağlık sektörü alanına uyarlandığ 1 için ölçeğin yapısal geçerliliği yeniden test edilmiştir. SPSS yöntemi ile yapılan güvenirlik analizinde anketin iç tutarlılığ için Cronbach Alfa değeri ,846 olarak ölçülmüştür. Bu değer ölçekte kullanılan maddelerin kabul edilebilir düzeyde ve birbirleriyle tutarlı olduğunu göstermektedir. Her bir boyutun Cronbach Alfa değerleri ise: memnuniyet .867, güven .774, bağllık .739 ve karşllıklı kontrol .645 şeklinde 
ölçülmüştür. Anket ölçeğinde yer alan maddelerden bazıları kontrol amaçlı olarak birbirleriyle ters orantılı verilmiştir.

Faktör analizi sonuçlarına göre ölçekte yer alan datalar faktör analizi için uygun bulunmuştur (Kaiser-MeyerOlkin Measure of Sampling Adequacy $=, 753$; Bartlett's Test of Sphericity $=, 000$ ). Faktör analizi sonucuna göre özdeğeri l'in üzerinde olan 4 bileşen saptanmıştır ve bu bileşenler ölçülmeye çalışılan değerin \% 63'ünü açılayabilmektedir. Dolayısıyla, kümülatif varyans \%50'nin üzerinde bulunduğu için ölçek uyarlamasının geçerli olduğu söylenebilir.

Ölçekte kullanılan her bir maddenin geçerliliğini test etmek için ise faktöriyel varyanslara bakılmıştır. Anket ölçeğinde bulunan maddelerin faktöriyel varyansları en düşük .468 ve en yüksek .748 aralığında ölçülmüştür. Ankette kullanılan her bir maddenin ortak faktör varyansının 0.30 'dan yüksek çıkması ölçeğin yapısal geçerliliğini sağlamıştır.

\section{Araştırma Sonuçları}

İlk araştırma sorusu, sağlık hizmeti alıcılarının sağlık kuruluşları tercihlerine yönelik isteklerini ilişkisel boyutlar ile tanımlamayı amaçladığı için her bir ilişkisel boyut ölçeğine yönelik genel ortalamalar ölçülmüştür. Kamu sağlık kuruluşlarındaki en yüksek ilişkisel sonuç ortalamasını karşılıklı kontrol $(\mathrm{M}=3.74$, SS = .69) unsuru vermiştir. İkinci sırada memnuniyet $(\mathrm{M}=3.60, \mathrm{SS}=.79)$, üçüncü sırada güven $(\mathrm{M}=3.56, \mathrm{SS}=.78)$, dördüncü sırada ise bağl1lık $(\mathrm{M}=3.51, \mathrm{SS}=.80)$ unsuru yer almıştır. Sonuçlar tablo 1'de gösterilmektedir.

Tablo 1

Sağlık Hizmeti Alıcılarının Kamu Sağlık Kuruluşları ile Olan İlişkisel Boyutları

\begin{tabular}{lccc}
\hline İlişkisel Boyutlar & Sayı & Ortalama & Std. Sap. \\
\hline Bağlılık & 132 & 3,5136 &, 80274 \\
Güven & 132 & 3,5631 &, 78621 \\
Memnuniyet & 132 & 3,6061 &, 79115 \\
Karşılıklı Kontrol & 132 & 3,7409 &, 69972 \\
\hline
\end{tabular}

Özel sağlık kuruluşlarındaki en yüksek ilişkisel sonuç ortalamasını yine karşılıklı kontrol $(\mathrm{M}=3.70, \mathrm{SS}=.71)$ unsuru vermiştir. İkinci sırada memnuniyet $(\mathrm{M}=3.66, \mathrm{SS}=.74)$, üçüncü sırada bağlllık $(\mathrm{M}=3.48, \mathrm{SS}=.61)$, dördüncü sırada ise güven $(\mathrm{M}=3.38, \mathrm{SS}=.62)$ unsuru yer almıştır.

Tablo 2

Sağlık Hizmeti Alıcılarının Özel Sağlık Kuruluşları ile Olan İlişkisel Boyutları

\begin{tabular}{lccc}
\hline İlişkisel Boyutlar & Sayı & Ortalama & Std. Sap. \\
\hline Bağl1lık & 117 & 3,4821 &, 61260 \\
Güven & 117 & 3,3803 &, 62700 \\
Memnuniyet & 117 & 3,6650 &, 74084 \\
Karşılıklı Kontrol & 117 & 3,7043 &, 71756 \\
\hline
\end{tabular}


Tablo 1 ve tablo 2'de ki sonuçlara göre tüm ilişkisel sonuçlar olumludur ve birbirlerine oldukça yakındır. Araştırma verilerine göre her iki kuruluşta da iletişimsel sürece yönelik "karşılıklı kontrol" boyutu en güçlü pozitif etkiyi sağlamıştır. İletişimsel sürecin ise öncelikle karşılıklı kontrol boyutuyla ilişkili olduğu söylenebilir.

Araştırma sorusu 2’ye yanıt aramak içim sağlık hizmeti alıcılarının Kamu sağlık kuruluşları ile olan ilişkisel boyutları (bağlılık, güven, memnuniyet, karşılıklı kontrol) arasındaki korelasyona bakılmıştır. Sonuçlar tablo 3'de gösterilmektedir.

Tablo 3

Sağlık Hizmeti Alıcılarının Kamu Sağlık Kuruluşları ile Olan İlişkisel Sonuçları Arasındaki Korelasyon

\begin{tabular}{|c|c|c|c|c|c|}
\hline İlişkisel Boyutlar & & Bağlılık & Güven & Memnuniyet & Karşılıklı Kontrol \\
\hline \multirow{3}{*}{ Bağlılık } & Pearson Correlation & 1 &, $713^{* *}$ & $529^{* *}$ &, $708^{* *}$ \\
\hline & Sig. (2-tailed) & &, 000 &, 000 & ,000 \\
\hline & $\mathrm{N}$ & 132 & 132 & 132 & 132 \\
\hline \multirow{3}{*}{ Güven } & Pearson Correlation &, $713^{* *}$ & 1 &, $680^{* *}$ &, $681^{* *}$ \\
\hline & Sig. (2-tailed) &, 000 & & 000 &, 000 \\
\hline & $\mathrm{N}$ & 132 & 132 & 132 & 132 \\
\hline \multirow{3}{*}{ Memnuniyet } & Pearson Correlation &, $529^{* *}$ & $680^{* *}$ & 1 &, $722^{* *}$ \\
\hline & Sig. (2-tailed) &, 000 & 000 & &, 000 \\
\hline & $\mathrm{N}$ & 132 & 132 & 132 & 132 \\
\hline \multirow{3}{*}{ Karşılıklı Kontrol } & Pearson Correlation &, $708^{* *}$ &, $681^{* *}$ &, $722^{* *}$ & 1 \\
\hline & Sig. (2-tailed) &, 000 & 000 &, 000 & \\
\hline & $\mathrm{N}$ & 132 & 132 & 132 & 132 \\
\hline
\end{tabular}

Tablo 3'de ki sonuçlara göre tüm ilişkisel boyutlar arasında anlamlı bir korelasyon bulunmuştur. En yüksek korelasyon karşılıklı kontrol ve memnuniyet arasında (,722) ölçülürken ikinci sırada güven ve bağlllık (.713) yer almıştır.

Özel sağlık kuruluşlarındaki sonuçlarda ise ilişkisel boyutlar arasında yine anlamlı bir korelasyon bulunmuştur. En yüksek korelasyon yine karşılıklı kontrol ve memnuniyet $(, 746)$ arasındayken, ikinci sırada güven ve memnuniyet (.577) yer almaktadır. Sonuçlar tablo 4'de gösterilmektedir. 
Tablo 4

Sağlık Hizmeti Alıcılarının Özel Sağlık Kuruluşları ile Olan İlişkisel Sonuçları Arasındaki Korelasyon

\begin{tabular}{|c|c|c|c|c|c|}
\hline \multicolumn{2}{|c|}{ İlişkisel Boyutlar } & \multirow{2}{*}{$\frac{\text { Bağlılık }}{1}$} & \multirow{2}{*}{$\frac{\text { Güven }}{, 509^{\star *}}$} & \multirow{2}{*}{$\frac{\text { Memnuniyet }}{, 490^{* *}}$} & \multirow{2}{*}{$\frac{\text { Karşıliklı Kontro }}{, 434^{* *}}$} \\
\hline & Pearson Correlation & & & & \\
\hline \multirow[t]{3}{*}{ Bağlılık } & Sig. (2-tailed) & & ,000 &, 000 &, 000 \\
\hline & $\mathrm{N}$ & 117 & 117 & 117 & 117 \\
\hline & Pearson Correlation &, $509^{* *}$ & 1 &, $577^{* *}$ &, $562^{* *}$ \\
\hline \multirow[t]{3}{*}{ Güven } & Sig. (2-tailed) &, 000 & &, 000 &, 000 \\
\hline & $\mathrm{N}$ & 117 & 117 & 117 & 117 \\
\hline & Pearson Correlation & $490^{* *}$ &, $577^{* *}$ & 1 &, $746^{* *}$ \\
\hline \multirow[t]{3}{*}{ Memnuniyet } & Sig. (2-tailed) &, 000 & ,000 & &, 000 \\
\hline & $\mathrm{N}$ & 117 & 117 & 117 & 117 \\
\hline & Pearson Correlation & $434^{* *}$ &, $562^{* *}$ &, $746^{* *}$ & 1 \\
\hline \multicolumn{2}{|c|}{ Karşılıklı Kontrol Sig. (2-tailed) } &, 000 &, 000 &, 000 & \\
\hline & $\mathrm{N}$ & 117 & 117 & 117 & 117 \\
\hline
\end{tabular}

Tablo 3 ve tablo 4'deki sonuçlara göre tüm ilişkisel sonuçlar birbirleriyle ilişkilidir. Bu yüzden ilişkisel sonuçları güçlendirmenin veya değiştirmenin aynı zamanda sağlık kuruluşlarına olan algıyı değiştirmek veya güçlendirmek anlamına gelebileceği söylenebilir.

Araştırma sorusu 3'e yanıt aramak için sağlık hizmeti alıcılarının sağlık kuruluşları ile olan ilişkisel boyutlarının derecesi özel ve kamu sağlık kuruluşlarına göre karşılaştırılmıştır. \% 95 güven aralığında yapılan Anova testi sonucuna göre iki farklı kuruluşun sağlık hizmeti alıcıları ile olan ilişkisel sonuçları olarak bağlılık $(\mathrm{F}=985,479>0,05)$; güven $(\mathrm{F}=927,548>0,05)$; memnuniyet $(\mathrm{F}=565,903>0,05)$ ve karşıllklı kontrol $(\mathrm{F}=877$ $, 585>0,05)$ ortalamaları arasındaki fark istatistiksel olarak anlamlı bulunmamıştır.

İlişkisel sonuçların sağlık kuruluşlarının kurumsal itibarları ile olan ilişkisini ölçmek için her bir ilişkisel boyutun kurumsal itibar ile arasındaki korelasyona bakılmıştır. Tablo 5'de gösterildiği gibi ilişkisel sonuçlar ile kurumsal itibar arasında anlamlı bir korelasyon vardır. Kurumsal itibarın karşılıklı kontrol ile ,560; güven ile ,565; memnuniyet ile ,596; ve bağlılık ile ,590 korelasyon katsayısı vardır. Tüm bu oranlar birbirlerine oldukça yakındır. 
Tablo 5

İlişkisel Boyutlar ile Özel Sağlık Kuruluşlarının İtibarları Arasındaki Korelasyon

\begin{tabular}{llccc}
\hline & İlişkisel Boyutlar & Sayı & $\begin{array}{c}\text { Korelasyon } \\
\text { Katsayısı }\end{array}$ & Sig. \\
\hline \multirow{3}{*}{ Kurumsal İtibar } & \& Karşılıklı Kontrol & 117 &, 560 &, 000 \\
& \& Güven & 117 &, 565 &, 000 \\
& \& Memnuniyet & 117 &, 596 &, 000 \\
& \& Bağllık & 117 &, 590 &, 000 \\
\hline
\end{tabular}

Tablo 6'da gösterildiği üzere Kamu sağlık kuruluşlarının itibarları ile ilişkisel sonuçlar arasında birbirine benzer şekilde anlamlı bir korelasyon katsayısı vardır. Kurumsal itibarın karşılıklı kontrol ile ,543, güven ile ,531, memnuniyet ile ,523, bağll1ık ile ,552 korelasyon katsayısı vardır.

Tablo 6

İlişkisel Sonuçlar ile Kamu Sağlık Kuruluşlarının İtibarları Arasındaki Korelasyon

\begin{tabular}{llccc}
\hline & İlişkisel Boyutlar & Sayı & $\begin{array}{c}\text { Korelasyon } \\
\text { Katsayısı }\end{array}$ & Sig. \\
\hline \multirow{3}{*}{ Kurumsal İtibar } & \& Karşılıklı Kontrol & 132 &, 543 &, 000 \\
& \& Güven & 132 &, 531 &, 000 \\
& \& Memnuniyet & 132 &, 523 &, 000 \\
& \& Bağllık & 132 &, 552 &, 000 \\
\hline
\end{tabular}

\section{Sonuç ve Öneriler}

Halkla ilişkiler uygulamalarının öncelikle iletişimsel süreç ile yani karşılıklı kontrol boyutuyla ilişkili olduğu söylenebilir. Bu yüzden araştırma verilerine göre her iki kuruluşta da iletişimsel sürece yönelik "karşılıklı kontrol” boyutu en güçlü pozitif etkiyi sağlamıştır. Karşlıklı kontrolün ise her iki kuruluşta da en fazla "memnuniyet" boyutuyla ilişkili olduğu sonucuna ulaşılmıştır. Bu yüzden sağlık hizmeti alıcıları açısından sağlık kuruluşlarında halkla ilişkiler algılamalarının en fazla karşılıklı kontrol ve memnuniyet boyutları üzerinde değerli olduğu söylenebilir.

Halkla ilişkiler uygulamalarının kalitesini ve bu uygulamaların hedef kitleler üzerindeki etkinliğini belirlemek oldukça zor ve karmaşıktır. Güven, memnuniyet, bağlılık ve karşılıklı kontrol boyutları ise halkla ilişkiler araştırmalarında en çok kullanılan unsurlardır. Bunların etki faktörleri, birbirleri arasındaki bağlantılar ve neden-sonuç ilişkileri farklı sektörlerde araştırılmıştır. Araştırma bulgularına göre tüm bu boyutların birbirleriyle ilişkili olduğu ve sağlık kuruluşlarının kurumsal itibarlarını etkileyebileceği söylenebilir. Diğer yandan bu boyutlar kendi aralarında çelişkilide olabilir. Çünkü kurumsal bağlamda değerlendirilen bu faktörler kurumsal imaj, kurumsal itibar ve kurumsal kimlik gibi faktörlerle de ilişkilidir ve bunlar sağlik kuruluşlarının kurumsallaşması için gereklidir. 
Araştırma bulguları ışığında sağlık kuruluşlarında halkla ilişkiler uygulamalarının değerinin ortaya çıkartılması için ve sağlı kuruluşlarının hedef kitleleriyle olan ilişkilerinin kalitesinin arttırılabilmesi için gerekli olan önermeler şu şekildedir:

Memnuniyet: Sağlık kuruluşlarında halkla ilişkilerin etkinliğini ölçmek diğer sektörlere göre farklılık gösterebilmektedir. Çünkü sağlık kuruluşlarında halkla ilişkiler uygulamalarının kalitesinin ve öneminin ortaya çıkartılması kurumsal amaçlarla olan ilişkilerin öneminin ortaya çıkartılması ile paralellik gösterebilmektedir. Bu nedenle sağlık kuruluşlarında halkla ilişkiler uygulamalarının etkinliği sadece hedef kitlelerin memnuniyeti üzerinden yapılabilmektedir. Hedef kitleler öncelikle bir kuruluşla olan ilişkilerinden memnun kalırlarsa, sağlık kuruluşları tarafından değerli olduklarını ve saygı gördüklerini hissederlerse ilişkilerini devam ettirirler. Memnuniyete yönelik olarak ise hedef kitlelerin beklentilerinin, endişelerinin, algılarının, tutumlarının ve bunların davranışsal sonuçlar üzerine ayırt edici etkilerinin belirlenmesi gerekmektedir. Farklı sosyal, kültürel ve demografik özelliklere sahip olan hedef kitlelere yönelik ortak stratejiler geliştirilmesi gerekmektedir. Diğer yandan sağlık kuruluşlarında memnuniyet unsurunun çok boyutlu olabileceği söylenebilir. Memnuniyeti sağlamak için bu duyguya nelerin etki ettiğinin anlaşılması gerekmektedir. Çünkü sağlık kuruluşlarına karşı duyulan memnuniyet duygusunun psikolojik ve sosyal gerçeklikleri vardır. Diğer yandan sağlık kuruluşlarında halkla ilişkiler uygulamalarına yönelik olarak duyulan memnuniyet duygusunun tek başına yeterli olamayabileceği söylenilebilir. Bu yüzden ilişkisel memnuniyeti diğer ilişkisel sonuçlarla beraber değerlendirmek gerekmektedir.

Güven: Sağlık kuruluşlarına karşı duyulan güven en önemli faktörlerden biri olarak ölçülmüştür. Güvenilirliği arttırmak için etkili kişilerarası iletişim yöntemleri ile diyaloğa dayalı simetrik bir süreç kullanılması, sorumluluklara dikkat edilmesi, hesap verebilir ve şeffaflık içerecek şekilde bilgi akışının sağlanması ve özel hayatın gizliliğine riayet edilmesi gibi yaklaşımlar sağlık hizmeti alıcılarına değer verildiğinin gösterilmesi açısından önemlidir. Ayrıca araştırma sonucu sağlık kuruluşlarına olan güven duygusunun destekleyici davranışlara yönelik en önemli unsur olduğunu ortaya çıkarmıştır. Bu yüzden sağlık kuruluşları halkla ilişkiler uygulamalarıyla güven unsurunu daha kapsayıcı hale getirerek arttırmalıdırlar. Sağlık kuruluşlarının çok farklı sosyokültürel ve demografik özelliklere sahip bireylerden oluşan hedef kitlelerinin farklılıkları hakkında bilgi sahibi olmak etkili iletişimsel becerilerin geliştirilmesi ve sürdürülmesi için gereklidir. Hedef kitle ilişkilerinin güven unsuru açısından geliştirilmesi için sağlık kuruluşlarındaki birim farklılıklarına göre ihtiyaç, talep ve beklentilere yönelik olarak çok farklı yaklaşımlar kullanılabilir. Örneğin, sağlık kuruluşları tarafından kurumsal itibara ve imaja odaklanılması güven unsuru için yeterli görülebilmektedir. Oysaki sağlık kuruluşlarında, farklı deneyimlerden dolayı, özel stratejiler gerektiren psikolojik unsurları göz ardı etmemek gerekmektedir. Bu nedenle güven unsurunun oluşturulması için kaygı ve endişelerin giderilmesi gerekmekte, etik, ahlaki ve sosyal açıdan hesap verebilir bir şekilde davranmak gerekmektedir.

Hedef kitlelerin duygu ve düşünceleri zaman içinde değişebilir. Üstelik ilişkisel sonuçlar birçok sosyal faktörden etkilenebilir. Tüm halkla ilişkiler uygulamalarının sonucuna yönelik olarak ise öncelikle güven unsuru oluşturmak gerektiği söylenebilir. Sağlık kuruluşlarının hizmet alıcılarıyla etkili iletişim kurması güven duygusunu oluşturmak ve arttırmak için gereklidir. Ancak güven oluşturmak, özellikle de sağlık sektöründe, sadece halkla ilişkiler uygulayıcılarının kontrolünde olan bir durum değildir. Bu yüzden sağlık hizmeti alıcıları üzerinde güven unsurunu neyin oluşturduğuna ve güvenin nasıl arttırılacağına yönelik ölçümler yapılmalı, olumlu ve olumsuz etkiler not edilmelidir. Chia'ye (2004) göre güven, karşılıklı olarak anlaşıldığında ve değer verildiğinde ilişkilerin geliştirilmesine ve sürdürülmesine yardımcı olabilir. Aksi takdirde, güven, ilişkilerin gelişmesine değil, esas olarak sonuçlara bağlı olacaktır. 
Bağhlık: Bağlılık unsuru sağlık kuruluşlarının hedef kitleleri ile olan ilişkilerinin kalitesine yönelik bir sonuçtur. Sağlık kuruluşlarında halkla ilişkilerin değerinin ortaya çıkartılması için bağlılığa yönelik yararlarının ortaya çıkartılması gerekmektedir. Sağlık kuruluşlarında hedef kitle ayrımlarının sınıflandırılması ve tanımlanması, bu ayrımlar arasında eşitliğin sağlanması ve ortak yaklaşımların uygulanması değer yaratma sürecine ve bağll1ık ilkesine katkı sağlayacaktır. Bağlılık duygusal, bilişsel ve davranışsal niyetleri içermektedir. Halkla ilişkiler uygulamalarına yönelik iletişimsel sürecin miktarının ve kalitesinin daha fazla bağlılık hissi yaratabileceği söylenebilir. İlişkisel sonuçlar bilişsel, duygusal ve davranışsal süreçlere yönelik tutumları ölçen fizyolojik ve psikolojik etkilere göre belirlenebilen oldukça karmaşı unsurlardır. Tüm bunlar deneyimsel öğrenme süreci ile oluşur ve zaman içinde değişebilir. Bilişsel ve duygusal tutumların davranışsal bağlılığın bir öncüsü olduğu söylenebilir. Ki ve Hon (2007) ve Grunig ve Hung-Baesecke (2015) yapmış oldukları araştırmada ilişki kalitesi algısının halkın tutumu ve davranışsal niyetleri üzerinde etkili olduğu sonucuna ulaşmıştır. Bu yüzden önemli olan bunların tutumlara nasıl yansıdığının araştırılmasıdır. Çünkü tutumlar tüm değişkenleri içermektedir. Olumlu tutumsal sonuçlar ile sağlık hizmeti alıcıları sağlık kuruluşlarının savunucuları ve destekçisi olabilirler. Ağızdan ağıza iletişim ve sosyal medya kanalarında olumlu yorumlamalar şeklinde oluşturulacak bir iletişimin ise davranışsal desteği arttırabileceği ve sağlık kuruluşlarının kurumsal kimliklerine yönelik değer oluşturabileceği söylenebilir (Çelebi, 2020b)

Karşılıklı Kontrol: Sağlık kuruluşları hedef kitleleri ile olan ilişkilerinde daha fazla güç sahibi olduğu düşünebilir. Halkla ilişkiler uygulayıcıları kuruluşlar ve hedef kitleleri arasında arzulanan karşılıklı olumlu ve yararlı ilişkisel sonuçlara ulaşabilmek için bir aracı olarak işlev görmektedir. Halkla ilişkiler uygulayıcıları sağlık kuruluşlarında sadece kurumsal amaçlara değil aynı zamanda kamu yararına da hizmet eden ilişkisel bir süreçle faaliyetlerini sürdürmelidir. Bu yüzden sadece diyalog oluşturmak ve etkileşim kurmak yeterli olmamaktadır. Hedef kitlelerin görüşlerinin dikkate alınması ve karşılıklılık ilkesinin uygulanması etkileşim kurmak kadar değerlidir. Karşılıklılık ilkesinin daha olumlu ve uzun süreli ilişkiler yaratacağı söylenebilir. Karşılıklılık için sağlık kuruluşlarının geribildirimler ile hedef kitlelerinin ihtiyaç ve endişelerine yönelik görüş ve önerilerini dikkate alması ve bunun için ikna edici, açı, doğrudan ve aktif bir diyalog başlatması gerekmektedir. Halkla ilişkiler literatüründe açık, özgün ve şeffaf iletişim yoluyla kuruluşlar ve kamuoyu arasında güçlü ilişkiler kurmak, mükemmel halkla ilişkilerin mihenk taşı olarak görülmüştür (Grunig ve Grunig, 2008; Taylor ve Kent, 2014). Böylece hedef kitlelerinin kendilerini değerli hissetmeleri sağlatılmalıdır. Aksi halde kendilerini geçici ve daha az değerli bir birey olarak görebilirler. İlişkileri geliştirmek hedef kitle gruplarını tanımayı ve onlara nasıl değer verildiğini göstermeyi gerektirir. Diğer yandan özel hayatın gizliliği ilkesine uyulması ve bilgilerin nasıl korunacağı gibi nedenler göz ardı edilmemelidir. Sağlık hizmeti alıcılarının sağlık kuruluşlarına karşı tutumlarının halkla ilişkiler algılamalarıyla arasında çok farklı faktörler olabilir. Bu faktörlere yönelik olarak karşılıklı değerler yaratmak, psikolojik süreçleri tanımlamak, kişilerarası etkili iletişim tekniklerinden yararlanmak, samimiyetlik kurmak vb. stratejiler iletişimsel kalitenin arttırılmasına katkı sağlayabilir. Çünkü ilişki yönetimi genellikle iletişimsel etkinlik ile ilişkilendirilmektedir (Kim ve Rhee, 2011). Bir ilişki yönetimi aracı olarak kişilerarası iletişim yeteneği önemli bir kaynaktır. Bu sayede olumlu beşeri ilişkiler kurulur, geliştirilir ve sürdürülür. Halkla ilişkiler uygulamaları ile kurulan iletişimsel süreç sadece bilgi alışverişinde bulunma değil aynı zamanda olumlu tutumsal algılar oluşturmaya yönelik bir süreçtir. Sağlık hizmeti alıcılarının kaygı ve endişeleri bilişsel, duygusal ve davranışsal tutumlarını etkileyebilir. Olumsuz duyguları gidermek veya en aza indirgemek sağlık sektöründe halkla ilişkiler uygulayıcılarının üzerinde durmasi gereken temel konulardan biridir.

Halkla ilişkiler çalışanları temsil ettikleri kuruluşların amaçlarına hizmet etmenin yanı sıra toplum geneline de katkıda bulunabilecek ilişkisel sonuçlara odaklanan bir süreçle faaliyetlerini sürdürmelidir. Sağlık kuruluşlarının hizmet alıcıları ile olan ilişkilerinin kalitesinin geliştirilmesi halkla ilişkiler uygulayıcılarının mesleki başarı potansiyelinin önemli bir göstergesidir. Bunun için halkla ilişkiler uygulayıcıları son derece gelişmiş etkili iletişim becerilerine sahip olmalıdır. İletişimsel süreçte aktif dinleme ve etkili geribildirim 
önemlidir. İletişimsel sürecin kalitesini arttırmak ve etkili iletişim stratejileri geliştirebilmek için kapsayıcı ve tutarlı mesajlar verilmesi gerekmektedir.

Sağlık kuruluşlarının halkla ilişkiler çalışmaları aracılığıyla tüm hedef kitleleriyle ilişkilerini geliştirmeye odaklanması gerekmektedir. Sağlık kuruluşlarının sağlık hizmeti alıcılarıyla olan ilişkilerinin kalitesinin uzun vadeli ve sürdürülebilir olabilmesi için ilişkisel sonuçların nasıl oluştuğu anlaşılmalı, bu ilişkisel sonuçların zamanla nasıl değişebileceğine yönelik ölçümlemeler yapmalı ve bu ilişkisel sonuçları geliştirmeye zaman ayrılmalıdır. Çünkü halkla ilişkilerde ilişki yönetimi hedef kitle odaklı bir yaklaşım gösterildiğinde başarıya ulaşabilmektedir (Ni ve diğerleri, 2018). Bunları yaparken etik ve ahlaki değerlere uygun davranılması, dürüstlük ve iyi niyetlilik gösterilmesi, sağlık hizmeti alıcılarının tüm ihtiyaç ve beklentilerinin anlaşılması ve bunlara imkânlar dâhilinde cevap verilebilmesi, iyi kurumsal temsilcilere sahip olunması vb. stratejiler sağlık hizmeti alıcılarına değer verildiğinin gösterilmesi açısından önemlidir. .

Sağlık kuruluşlarında halkla ilişkiler uygulayıcıları ilişkisel sonuçlar olarak memnuniyet, güven ve bağlılığın nasıl kurulacağı ve bunların nasıl korunabileceği konusunda tavsiyeler verilmesinden sorumludur. Ancak bu tutumlar sağlık kuruluşlarında oldukça karmaşık bir takım algılar sonucunda oluşmaktadır. Bu yüzden bu tutumların algılanmasına etki edebilecek tüm faktörlerin iyice anlaşılması gerekmektedir.

Gelecek araştırmalarda sağlık hizmeti alıcılarının sağlık kuruluşlarıyla olan ilişkisel sonuçlarını etkileyebilecek psikolojik faktörlerin nedenleri ve zaman içinde bunların nasıl değiştiği araştırmalıdır. Sağlık hizmeti alıcılarının geçmiş tecrübeleri, coğrafi ve kültürel farklılıklar gibi nedenler ve demografik unsurlar ileriki araştırmalara dâhil edilebilir. Ayrıca ilişki geliştirme stratejilerin kalitesini belirlemek ve sağlık kuruluşlarında bu ilkeleri oluşturabilmeye yönelik stratejiler geliştirebilmek için daha fazla araştırmaya ihtiyaç duyulmaktadır.

\section{Kaynakça}

Chia, J. (2004). Is trust a necessary component of relationship management?. Journal of Communication Management, 9(3), 277-285. doi:10.1108/13632540510621515

Coombs, W.T. ve Holladay, S.J. (2007). The negative communication dynamic. Journal of Communication Management, 11(4), 300-312. Doi:10.1108/13632540710843913

Çelebi, E. (2019). Halkla ilişkiler uygulamaları nasıl olmalı?. Ankara: Nobel Akademik Yayıncılık.

Çelebi, E. (2020a). Kurumsal halkla ilişkilerin etkinliğini ölçme: STK gönüllüleri üzerine bir araştırma, Selçuk İletişim, 13(1), 180-196. Erişim adresi: https://dergipark.org.tr/en/pub/josc/issue/52040/607432

Çelebi, E. (2020b). Sosyal medya iletişiminin kurumsal itibar algısı üzerindeki rolü, Pamukkale Üniversitesi Sosyal Bilimler Enstitüsü Dergisi, 41, 108-118. Doi: 10.30794/pausbed.737870

Dhanesh, G.S. ve Duthler, G. (2019). Relationship management through social media influencers: Effects of followers' awareness of paid endorsement. Public Relations Review, 45(3), 1-13. doi: 10.1016/j.pubrev.2019.03.002

Duğan, Ö. ve Uludağ, A. (2015). Sağlık çalışanlarının halkla ilişkilere bakışı: Selçuk üniversitesi tıp fakültesi örneği, Selçuk Üniversitesi Sosyal Bilimler Enstitüsü Dergisi, 34, 41-51. Erişim adresi: http://dergisosyalbil.selcuk.edu.tr/susbed/article/view/1156 
Ferguson, M. A. (2018). Building theory in public relations: Interorganizational relationships as a public relations paradigm. Journal of Public Relations Research, 30(4), 164-178. doi: 10.1080/1062726X.2018.1514810

Gordon, C.G. ve Kelly, K.S. (1999). Public relations expertise and organizational effectiveness: A study of U.S. hospitals. Journal of Public Relations Research, 11(2), 143-165. doi: 10.1207/s1532754xjprr1102_03

Grunig, J.E. ve Grunig, L.A. (2008). Excellence theory in public relations: Past, present, and future. In: Zerfass, A. Van Ruler, B. \& Sriramesh, K. (eds) Public Relations Research. Wiesbaden, 327-347. doi: 10.1007/978-3-531-90918-9_22

Grunig, J.E. ve Hung-Baesecke, C.J.F (2015). The effect of relationships on reputation and reputation on relationships: A cognitive, behavioral study. Ki, E.J., Kim, J.N. \& Ledingham, J.A. (eds.) Public relations as relationship management: A relational approach to the study and practice of public relations (63113), Routledge, New York And London

Heath, R. L. (2013). The journey to understand and champion OPR takes many roads, some not yet well traveled. Public Relations Review, 39(5), 426-431. doi: 10.0.3.248/j.pubrev.2013.05.002

Hon, L.C. ve Grunig, J.E. (1999). Guidelines for measuring relationships in public relations. Institute for Public Relations, 1-40. Erişim adresi: http://painepublishing.com/wpcontent/uploads/2013/10/Guidelines_Measuring_Relationships.pdf

Jo, S. (2018). In search of a causal model of the organization-public relationship in public relations. Social Behavior and Personality, 46(11), 1761-1770. doi: 10.2224/sbp.7022

Khodarahmi, E. (2009). Strategic public relations. Disaster Prevention and Management, 18(5), 529-534. doi: $10.1108 / 09653560911003723$

Ki, E. ve Hon, L.C. (2007). Reliability and validity of organization: Public relationship measurement and linkages among relationship Indicators in a membership organization. Journalism \& Mass Communication Quarterly, 84(3), 430-431. Doi:10.1177/107769900708400302

Ki, E.-J. ve Hon, L. (2007). Testing the linkages among the organization-public relationship and behavioral intentions. Journal of Public Relations Research, 19(1), 1-23. doi:10.1080/10627260709336593

Kim, J. N. ve Rhee, Y. (2011). Strategic thinking about employee communication behavior (ECB) in public relations: Testing the models of megaphoning and scouting effects in Korea. Journal of Public Relations Research, 23(3), 243-268. doi:10.1080/1062726X.2011.582204

Kim, D. (2018). Examining effects of internal public relations practices on organizational social capital in the Korean context: Mediating roles of employee-organization relationships. Corporate Communications: An International Journal, 23(1), 100-116. doi:10.1108/CCIJ-01-2017-0002

Ledingham, J.A. (2008). A chronology of organization-stakeholder relationships with recommendations concerning practitioner adoption of the relational perspective. Journal of Promotion Management, 14(3-4), 243-262. doi:10.1080/10496490802637846

Moorman, C., Zaltman, G. ve Deshpande, R. (1992). Relationships between providers and users of market research: The dynamics of trust within and between organizations. Journal Of Marketing Research, 29(3), 314-328. doi: 10.1177/002224379202900303 
Ni, L., Wang, Q. ve Sha, B-L. (2018). Intercultural public relations: Theories for managing relationships and conflicts with strategic publics. New York: Routledge.

Ni, L., Xiao, Z., Liu, W. ve Wang, Q. (2019). Relationship management as antecedents to public communication behaviors: Examining empowerment and public health among AsianAmericans. Public Relations Review, 45(5), 1-10. doi: 10.1016/j.pubrev.2019.101835

Park, H. ve Reber, B.H. (2010). Using public relations to promote health: A framing analysis of public relations strategies among health associations. Journal of Health Communication, 15(1), 39-54. doi: $10.1080 / 10810730903460534$

Pressgrove, G. N. ve McKeever, B.W. (2016). Nonprofit relationship management: Extending the organizationpublic relationship to loyalty and behaviors. Journal of Public Relations Research, 28(3-4), 193-211. doi: 10.1080/1062726X.2016.1233106

Public Relations Society of America (PRSA) Erişim adresi (11 Aralık 2020): https://www.prsa.org/about/allabout-pr

Sisson, D. C. (2015). Authentic relationship management to heighten control mutuality in social media. Doctoral dissertation, Erişim adresi: http://scholarcommons.sc.edu/etd/3608

Springston, J.K. ve Lariscy, R.A.W. (2005). Public relations effectiveness in public health institutions. Journal of Health and Human Services Administration, 28(2), 218-245. Erişim adresi: http://www.jstor.org/stable/41288065

Taylor, M. ve Kent, M.L. (2014). Dialogic engagement: Clarifying foundational concepts, Journal of Public Relations Research, 26(5), 384-398. doi: 10.1080/1062726X.2014.956106

Yıldırım Becerikli, S. (2013). Türkiye'de sağlık iletişimi üzerine yazılan lisansüstü tezlerin bibliyometrik analizi: Eleştirel bir bakış. Ankara Sağlık Hizmetleri Dergisi, 12(2), 25-36. doi: 10.1501/Ashd_0000000089

\section{Extended Abstract}

\section{Purpose}

In order to achieve the desired results regarding the effectiveness of public relations practices in health institutions, it is necessary to understand the needs, expectations and concerns of the healthcare recipients. Relational results in public relations can be used as a strategy that can measure the human relationships that health organizations have established with healthcare recipients. Strengthening the relational consequences of healthcare organizations with healthcare recipients may determine the emotional and behavioral support of healthcare recipients to healthcare organizations. The aim of this study is to explain the importance of relational dimensions in health institutions, to predict relational results with communicative skills, and thus to reveal the value of public relations in health institutions.

\section{Design and Methodology}

While creating the research questions, the scale developed by Grunig and Hunt (1999) for the Public Relations Institute was used. 5 items were used to measure the feeling of trust in the research scale. For example, "these healthcare provider employees treat healthcare healthcare recipients honestly and fairly." 4 items were used for 
the control mutuality. For example, “these healthcare professionals don't consider themselves superior when dealing with healthcare recipients". 5 items were used for the commitment. For example, "I generally prefer this health institution to receive health services". 6 items were used for the satisfaction. For example, "I am pleased to receive health service from this health institution".

Relational results are considered as an attitudinal dimension and independent variables. Within the scope of the research, the following questions were asked:

Research Question 1: With which relational dimension do healthcare recipients define their requests for the preferences of health institutions?

Research Question 2: What is the correlation between the relational outcomes (control mutuality, trust, satisfaction, loyalty) of health care recipients with healthcare organizations?

Research Question 3: Does the degree of relational dimensions of health service recipients with health institutions differ between public and private health institutions?

Research Question 4: Is there a relationship between relational results and the corporate reputation of health institutions?

Criterion sampling method was used in sample selection. The time required to develop an attitude towards the health institution from which service is provided was determined as 3 months, and the survey was applied to health service recipients who are over 18 years of age and volunteering to participate in the survey.

\section{Findings}

Since the first research question aims to define the requests of health service recipients towards the preferences of health institutions with relational dimensions, the general averages for each relational dimension item were measured. Control mutuality $(\mathrm{M}=3.74$, $\mathrm{SS}=.69)$ gave the highest average in public health institutions. Satisfaction $(\mathrm{M}=3.60, \mathrm{SS}=.79)$ ranked second, trust $(\mathrm{M}=3.56, \mathrm{SS}=.78)$ in the third, and commitment $(\mathrm{M}=$ $3.51, \mathrm{SS}=.80)$ in the fourth rank. The factor of control mutuality $(\mathrm{M}=3.70, \mathrm{SD}=.71)$ has the highest average in private health institutions. Satisfaction $(\mathrm{M}=3.66$, $\mathrm{SS}=.74)$ ranked second, commitment $(\mathrm{M}=3.48, \mathrm{SS}=$ $.61)$ in the third, and trust $(\mathrm{M}=3.38, \mathrm{SS}=.62)$ in the fourth rank. According to the research data, the "control mutuality" dimension towards the communicative process provided the strongest positive effect in both organizations. It can be said that the communicative process is primarily related to the control mutuality dimension.

For the 2nd research question, a significant correlation was found between all relational dimensions. While the highest correlation was measured between control mutuality and satisfaction (.722), the second was trust and commitment (.713). All relational dimensions were related to each other. Therefore, it can be said that strengthening or changing the relational dimensions can also mean changing or strengthening the perception towards health institutions.

In order to receive for an answer to research the 3rd question, the degree of relational dimensions of health service recipients with health institutions was compared according to private and public health institutions. According to the Anova test, the difference between commitment $(F=985,479>0.05)$; trust $(F=927,548>$ 
$0.05)$; satisfaction $(\mathrm{F}=565,903>0.05)$ and control mutuality $(\mathrm{F}=877,585>0.05)$ averages were not statistically significant in public and private health institutions.

Acoording to the results, there is a significant correlation between relational results and corporate reputation in both private and public health institutions.

\section{Research Limitations}

Future research should investigate the causes of psychological factors that may affect the relational results of health care recipients with healthcare institutions and how these have changed over time. Reasons such as the past experiences of healthcare recipients, geographical and cultural differences, and demographic factors can be included in future research. In addition, more research is needed to determine the quality of relationship development strategies and to develop strategies to establish these principles in health institutions.

\section{Implications (Theoretical, Practical and Social)}

Satisfaction: If health service recipients are satisfied with their relationship with an organization, they feel valued and respected by health institutions, they continue their relationships. With regard to satisfaction, it is necessary to determine the expectations, concerns, perceptions, attitudes of the health service recipients and their distinctive effects on behavioral results.

Trust: Trust in health institutions has been measured as one of the most important factors. Approaches such as using effective interpersonal communication methods and a symmetrical process based on dialogue, paying attention to responsibilities, ensuring accountability and transparency, and respecting the privacy of private life are important in terms of showing that healthcare clients are valued.

Commitment: The factor of commitment is a result of the quality of the relationships of health institutions with their healthcare recipients. In order to reveal the value of public relations in health institutions, it is necessary to reveal the benefits of commitment. It can be said that the amount and quality of the communicative process for public relations practices can create a greater sense of commitment.

Control Mutuality: Public relations practitioners should continue their activities in health institutions with a relational process that serves not only institutional purposes but also the public good. Therefore, it is not enough to just create a dialogue and interact. Considering the opinions of the healthcare recipients and applying the principle of reciprocity is as valuable as interacting. It can be said that the principle of control mutuality will create more positive and long-lasting relationships.

\section{Originality/Value}

Improving the quality of the relations of health institutions with their service recipients is an important indicator of the professional success potential of public relations practitioners. For this reason, public relations practitioners must have highly developed, effective communication skills. Active listening and effective feedback are important in the communicative process. In order to increase the quality of the communication process and to develop effective communication strategies, inclusive and consistent messages should be given. 
In order for the quality of the relationships of healthcare organizations with healthcare providers to be longterm and sustainable, it should be understood how relational results are formed, measurements should be made about how these relational results may change over time. Public relations practitioners in healthcare organizations are responsible for providing advice on how to build and maintain satisfaction, trust and loyalty as relational outcomes. However, these attitudes are formed as a result of quite complex perceptions in health institutions. Therefore, all factors that can affect the perception of these attitudes should be thoroughly understood.

Araştırmacı Katkısı: Engin ÇELEBİ (\%100). 